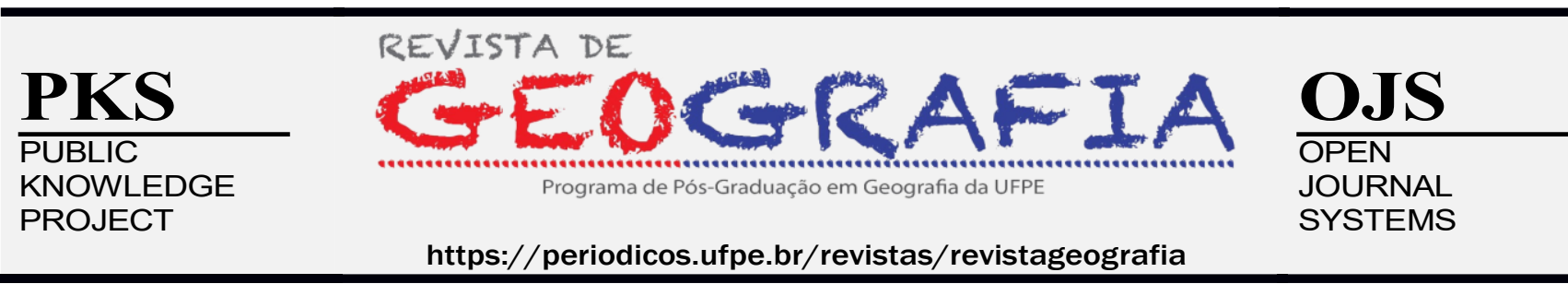

\title{
MAPEAMENTO DA FRAGILIDADE POTENCIAL NA BACIA HIDROGRÁFICA DO RIO MULATO, NO MÉDIO PARNAÍBA PIAUIENSE
}

\author{
Karoline Veloso Ribeiro ${ }^{1}$, Emanuel Lindemberg Silva Albuquerque ${ }^{2}$ \\ ${ }^{1}$ Universidade Federal do Ceará (UFC), karolvelosogeo@outlook.com, http://orcid.org/0000-0003-2697-6098 \\ ${ }^{2}$ Universidade Federal do Piaui (UFPI), lindemberg@ufpi.edu.br, http://orcid.org/0000-0003-3051-3301 \\ Artigo recebido em 07/05/2021 e aceito em 12/09/2021
}

\begin{abstract}
RESUMO
A análise da fragilidade dos ambientes naturais envolve um conjunto de informações e a proposição de diferentes modelos que perpassam, obrigatoriamente, pelo inventário do quadro natural. Nesta abordagem, a fragilidade potencial considera os aspectos naturais, caracterizando o equilíbrio dinâmico do ambiente sem considerar as influências da sociedade. Dessa forma, objetivou-se mapear a fragilidade potencial na bacia hidrográfica do Rio Mulato, no médio Parnaíba piauiense, a partir da proposta metodológica de Ross (1994). Para tal, considerou-se a análise integrada das variáveis ambientais, dando ênfase na geomorfologia, na declividade e nos tipos de solos. As informações de geologia e clima também foram analisadas com a finalidade de apresentar maior precisão aos resultados. Evidencia-se que as classes de fragilidade potencial muito baixa e baixa representam $54,9 \%$ da área total da bacia, enquanto as classes alta e muito alta representam $26,35 \%$. A classe média ocupa $18,75 \%$. Constatou-se que a declividade apresenta grande influência na determinação das áreas mais e/ou menos frágeis, uma vez que o relevo se encontra intimamente relacionado com o potencial cinético para o escoamento hídrico superficial e, consequentemente, com a instabilidade do ambiente, mediante processos erosivos que evidenciam certa instabilidade.
\end{abstract}

Palavras-chave: Planejamento Ambiental; Rio Parnaíba; Estado do Piauí.

\section{MAPPING OF POTENTIAL FRAGILITY IN THE MULATO RIVER WATERSHED IN THE MIDDLE PARNAÍBA PIAUIENSE}

\begin{abstract}
The analysis of fragility of the natural environments involves an ensemble of information and the proposition of different models that necessarily go through the inventory of the natural framework. In this approach, the potential fragility considers natural aspects, characterizing the dynamic equilibrium of the environment, disregarding the influences of society. Thus, the objective was to map the potential fragility in the Mulato River watershed in the middle Parnaíba piauiense, based on the methodological proposal of Ross (1994). Therefore, an integrated analysis of environmental variables was considered, with an emphasis on geomorphology, slop and soil types. The information on geology and climate was analyzed in order to get more precise results. It's
\end{abstract}




\section{Revista de Geografia (Recife) V. 38, $N^{\circ} .3,2021$}

evident that the classes of very low and low potential fragility represent $54.9 \%$ of the total area of the watershed, while high and very high classes represent $26.35 \%$. The middle class comprises $18.75 \%$. It was found that the slop has a great influence on the determination of the more and/or less fragile areas, since the relief is related to the kinetic potential of the surface runoff and, consequently, with the instability of environment, through erosive processes that evidence some instability.

Keywords: Environmental Planning. Parnaíba River. Piauí State.

\section{INTRODUÇÃO}

A bacia hidrográfica representa uma unidade de análise fundamental na Geografia, por se configurar um sistema. Sua utilização como recorte espacial básico para os estudos ambientais tem sido proposta de muitos autores, tendo em vista que as alterações decorrentes das interferências humanas sobre o ambiente refletem-se na bacia hidrográfica como um todo (BRASIL, 2009).

Logo, esta é um meio capaz de reunir um grande e variado conjunto ambiental que interage de maneira intensa e imediata em toda a sua extensão, provocando transformações nas estruturas morfológicas, climáticas, biogeográficas, pedológicas e geológicas circunscritas em seu interior (SOUZA, 2013).

Dentro da dinâmica dos sistemas naturais, a bacia hidrográfica revela-se como uma excelente área para os estudos voltados ao planejamento territorial/ambiental (GUERRA; CUNHA, 2006), pois demonstra o seu potencial enquanto unidade de análise e entidade territorial integrada, a qual torna um objeto de estudo de suma importância na aplicabilidade da ciência geográfica, sobretudo no contexto atual (LEITE; ROSA, 2009).

Nesse viés, a análise da fragilidade do ambiente é uma proposta de classificação voltada ao planejamento ambiental, cujo princípio básico é definir os diferentes níveis de fragilidade dos ambientes naturais e antropizados, em função do desenvolvimento das atividades humanas, já que estes são maiores ou menores face às suas características genéticas (ROSS, 1994).

Contudo, neste trabalho, a ênfase é dada à fragilidade potencial, indicando os níveis de fragilidade sob a ação dos processos morfogenéticos atuantes na paisagem, resultantes da correlação dos componentes físico-naturais. Dessa forma, objetivou-se mapear a fragilidade potencial na bacia hidrográfica do Rio Mulato, no médio Parnaíba piauiense, a partir da proposta metodológica de Ross (1994).

Entende-se como prioritária a reflexão sobre o entendimento da fragilidade potencial na área em estudo e sob a ótica sistêmica, pois é esta unidade de paisagem que permite, mais eficientemente, compreender e monitorar os diferentes níveis de fragilidade, bem como proporcionar informações 
que ajudem na melhor análise das principais atividades realizadas e/ou que auxiliem na gestão territorial.

\section{METODOLOGIA}

A metodologia aplicada para essa pesquisa tem base nos conceitos da análise da fragilidade ambiental, proposta por Ross (1994), utilizando-se das seguintes variáveis: classes de declividade, classes de solos, geologia e clima. O estudo integrado dessas variáveis possibilita a definição das classes de fragilidade potencial, apresentadas em cinco categorias: muito fraca, fraca, média, forte e muito forte.

Elaboração do mapa de declividade

Dados obtidos junto ao Serviço Geológico dos Estados Unidos (USGS), a partir da aquisição do Modelo Digital de Elevação (MDE), oriundo da missão Shuttle Radar Topography Mission (SRTM), utilizando técnicas de geoprocessamento e sensoriamento remoto. Este foi complementado por um mapa hipsométrico (importante para percepção e definição dos níveis altimétricos embutidos).

Inicialmente, os dados foram trabalhados no software ArcGis, na sua extensão ArcMap, onde foi possível a criação do MDE. Com as informações tridimensionais da área de estudo, foi possível a criação do mapa de declividade, por meio da ferramenta Surface analyst - Slope - Output (percent rise \%).

A declividade do terreno é expressa como a variação de altitude entre dois pontos do terreno, em relação à distância que os separa (TONELLO et al., 2006). Logo, a inclinação da feição superficial do terreno em relação ao plano horizontal, pode ser medida em graus $\left(0\right.$ a $\left.90^{\circ}\right)$ ou em porcentagem, apresentando grande influência no favorecimento ou não da erosão de solos. Neste estudo, fez-se uso da medida em porcentagem, seguindo a proposta de Ross (1994) e conforme é apresentado no quadro 1.

Quadro 1 - Classes de declividade

\begin{tabular}{|c|c|c|c|}
\hline Relevo & Classes (\%) & Categorias hierárquicas & Classes de Fragilidade \\
\hline Plano & $0-6$ & Muita fraca & 1 \\
\hline Suave Plano & $6-12$ & Fraca & 2 \\
\hline Suave Ondulado & $12-20$ & Média & 3 \\
\hline Ondulado & $20-30$ & Forte & 4 \\
\hline Forte Ondulado & $>30$ & Muito forte & 5 \\
\hline
\end{tabular}

Fonte: Ross (1994). Adaptado pelos autores (2020).

A melhor compreensão do algoritmo utilizado para extrair a declividade da imagem matricial, considera a triangulação composta pela altura, base e declividade, podendo ser expressos, em aplicação prática, pela seguinte equação: 


$$
D=\left(\frac{h}{b}\right) * 100
$$

Onde:

D: Declividade do terreno.

h: Altura entre dois pontos BC (equidistância vertical).

b: Distância horizontal entre dois pontos AC.

Atenta-se para o fato de que o cálculo da declividade em plataforma SIG é realizado com base nos valores altimétricos dos pixels adjacentes e segue o princípio da equação de declividade encontrada em Dunn e Hickey (1998). Após esta etapa, a informação de declividade foi reclassificada, o que permitiu delimitar os intervalos de classes de declividade, conforme a proposição de Ross (1994).

Elaboração do mapa de classes de solos

O mapa de classe de solos foi definido com base nos dados obtidos junto à Infraestrutura Nacional de Dados Espaciais (INDE, 2014), seguindo as diretrizes propostas pelo Sistema Brasileiro de Classificação de Solos da Empresa Brasileira de Pesquisa Agropecuária (EMBRAPA, 2013). No intuito de estimar as classes de fragilidade, aplicou-se a proposta metodológica de Ross (1994), conforme é retratado no quadro 2.

Quadro 2 - Tipos de solos e suas respectivas classes de fragilidade

\begin{tabular}{|c|c|c|}
\multicolumn{2}{|c|}{ Classes de fragilidade } & \multirow{2}{*}{ Tipos de Solos } \\
\hline Numérica & Qualitativa & \\
\hline 1 & Muito baixa & $\begin{array}{c}\text { Latossolo vermelho e Latossolo vermelho-amarelo de textura } \\
\text { argilosa }\end{array}$ \\
\hline 2 & Baixa & $\begin{array}{c}\text { Latossolo amarelo e vermelho-amarelo de textura média/argilosa } \\
\text { Chernossolos; Argissolo vermelho; Argissolo vermelho-amarelo } \\
\text { de textura média/argilosa; }\end{array}$ \\
\hline 3 & Média & Argissolo vermelho-amarelo de textura média/arenosa \\
\hline 5 & Alta & Argissolo com cascalho; Neossolo Litólico \\
\hline
\end{tabular}

Fonte: Ross (1994). Adaptado pelos autores (2020).

Destaca-se que a metodologia ainda sugere análises de informações sobre litologia e clima, sendo que estas são informações adicionais, utilizadas para a análise-síntese, com a finalidade de dar maior precisão aos resultados, uma vez que, analisadas em conjunto, são fatores decisivos no processo de intemperismo das rochas e na formação dos solos.

Para o mapeamento geológico fez-se uso de dados obtidos junto ao Serviço Geológico do Brasil (CPRM, 2010), enquanto os dados referentes ao clima, com base na pluviosidade média 
(mensal e anual), deu-se através da Agência Nacional de Águas (ANA, 2019), onde foi possível obter dados pluviométricos a partir de 5 (cinco) postos que se encontram no interior ou nas proximidades da área da bacia, seguindo uma escala temporal de onze anos (1992 a 2002).

Para a espacialização dos dados climáticos, realizou-se a conversão das linhas de isoietas em pontos, por meio da ferramenta Arctoolbox-Data Management Tools-Features - Features To Point. Assim, por meio dos pontos de referência pluviométrica, foi possível realizar a espacialização através do método Inverse Distance Weighted - IDW (Arctoolbox - spatial Analyst Tools - Interpolation $I D W)$.

A respeito dessa variável (regime pluviométrico), é importante mencionar que esta, mesmo não incluída na metodologia original aplicada por Ross (1994), foi incluída por Spörl (2007) e validada por aquele autor em estudos posteriores. Neste sentido, seguem as características pluviométricas para compreender as classes de fragilidade (quadro 3).

Quadro 3 - Classes de fragilidade das características pluviométricas

\begin{tabular}{|c|c|c|}
\hline \multicolumn{2}{|c|}{ Classes de fragilidade } & \multirow[t]{2}{*}{ Pluviometria } \\
\hline Numérica & Qualitativa & \\
\hline 1 & Muito baixa & $\begin{array}{l}\text { Situação pluviométrica com distribuição regular ao longo do ano, } \\
\text { com volumes não muito superiores a } 1000 \mathrm{~mm} / \mathrm{ano} \text {. }\end{array}$ \\
\hline 2 & Baixa & $\begin{array}{l}\text { Situação pluviométrica com distribuição regular ao longo do ano, } \\
\text { com volumes anuais não muito superiores a } 2000 \mathrm{~mm} / \mathrm{ano} \text {. }\end{array}$ \\
\hline 3 & Média & $\begin{array}{c}\text { Situação pluviométrica com distribuição anual desigual, com } \\
\text { períodos secos entre } 2 \text { e } 3 \text { meses de inverno, e no verão com } \\
\text { maiores intensidades de dezembro a marco. }\end{array}$ \\
\hline 4 & Alta & $\begin{array}{c}\text { Situação pluviométrica com 90\% das chuvas durante o primeiro } \\
\text { semestre do ano, nos meses de janeiro a abril, e irregularidade das } \\
\text { precipitações, em decorrência da má distribuição das chuvas, nos } \\
\text { meses que se seguem. }\end{array}$ \\
\hline 5 & Muito Alta & $\begin{array}{l}\text { Situação pluviométrica com distribuição regular, ou não, ao longo } \\
\text { do ano, com grandes volumes anuais ultrapassando } 2500 \mathrm{~mm} / \text { ano; } \\
\text { ou ainda, comportamentos pluviométricos irregulares ao longo do } \\
\text { ano, com episódios de chuvas de alta intensidade e volumes } \\
\text { anuais baixos, geralmente abaixo de } 900 \mathrm{~mm} / \text { ano (semiárido). }\end{array}$ \\
\hline
\end{tabular}

Fonte: Spörl (2007). Adaptado pelos autores (2020).

Cabe destacar que uma das análises que contribuem para o estudo é a visão multicritério, pois permite a investigação combinada de variáveis para gerar um mapa síntese como produto final. Dessa forma, a análise multicritério, a partir do método de álgebra de mapa, permitiu agrupar e classificar áreas que apresentem características de fragilidade semelhantes e díspares. Este método consiste na aplicação de operações aritméticas para associar várias camadas de modo a obter, como resultado, classificações que permitem análises diversas. 
Assim, para a modelagem da fragilidade potencial, em ambiente SIG, foi necessário um conjunto de ações para a manipulação dos dados. A combinação das variáveis se deu pela aplicação do método booleano de combinação de mapa, onde os planos de informação de formato vetorial foram convertidos para formato raster (matricial). Esse processo se deu através da caixa de ferramentas Arctoolbox - Conversion Tools - To raster - Feature to raster. Após converter todos os Shapefiles em arquivo raster, foi necessário reclassificar os valores/informações da coluna da tabela de atributos selecionada (Arctoolbox - Spatial Analyst Tools - Reclassify).

Para combinar as variáveis e criar o mapa de fragilidade potencial através da caixa de ferramentas (Arctoolbox - Spatial Analyst Tools - Raster Calculator), na opção Layers aparecem todas as variáveis disponíveis. Nesta etapa, cada uma das variáveis possuem os atributos de fragilidade acompanhados de números arábicos de 1 a 5 (1. Muito fraca; 2. Fraca; 3. Média; 4. Forte; 5. Muito forte). Por meio da sobreposição ponderada (Weighted Overley) dos atributos, com o cruzamento dos arquivos em formato raster, atribui-se, além das informações da fragilidade, os valores em porcentagem.

$\mathrm{Na}$ análise integrada, consideram-se os seguintes parâmetros por ordem de importância: Relevo/Solo/Clima. A figura 1 apresenta os procedimentos operacionais para a geração do mapa de fragilidade potencial da área estudada. Na sua metodologia, Ross (1994) hierarquizou a fragilidade por códigos, conforme é retratado no quadro 4.

Figura 1 - Esquema metodológico para a geração do mapa de fragilidade potencial na bacia hidrográfica do Rio Mulato, estado do Piauí

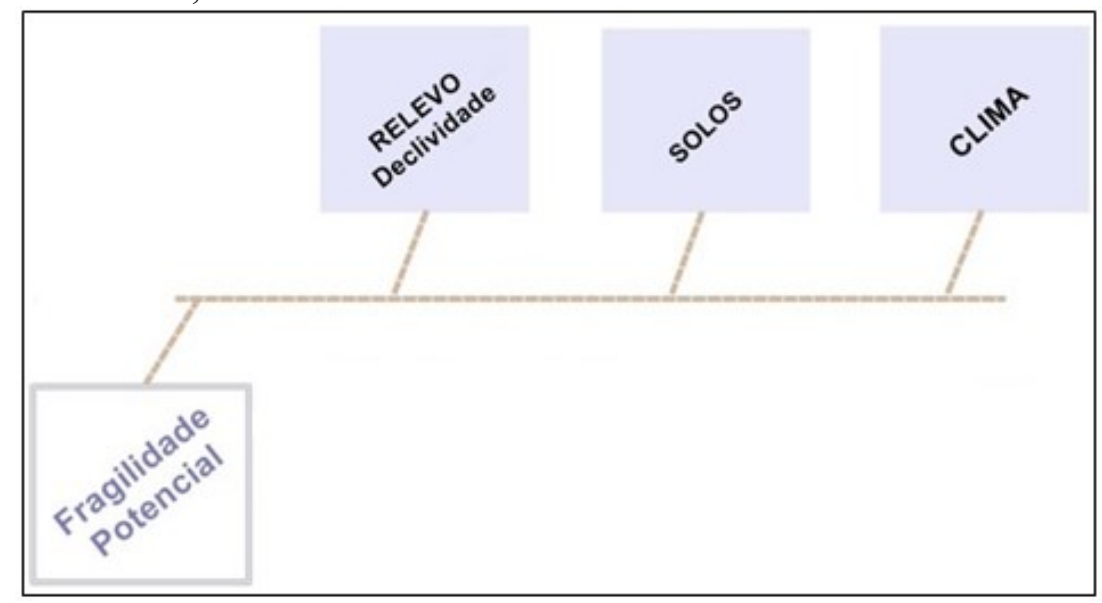

Organização: Autores (2020). 
Revista de Geografia (Recife) V. 38, No. 3, 2021

Quadro 4 - Proposição de Ross (1994) para as classes de fragilidade

\begin{tabular}{|c|c|c|}
\hline \multicolumn{1}{|c|}{ FRAGILIDADE } & QUALITATIVA & NUMÉRICA \\
\hline \multirow{4}{*}{ Fragilidade Potencial e Emergente } & Muito Baixa & 1 \\
\cline { 2 - 3 } & Baixa & 2 \\
\cline { 2 - 3 } & Média & 3 \\
\cline { 2 - 3 } & Alta & 4 \\
\cline { 2 - 3 } & Muito Alta & 5 \\
\hline
\end{tabular}

Fonte: Ross (1994). Adaptado pelos autores (2020).

É importante destacar que a metodologia utilizada nesta pesquisa possibilitou mapear a fragilidade potencial na bacia hidrográfica do Rio Mulato (BHRM) através de seus atributos, sendo expressa, hierarquicamente, em cinco classes de fragilidade, considerando as possíveis combinações entre as variáveis que classifica a fragilidade potencial através da interligação dos elementos naturais.

Do ponto de vista operacional, as geotecnologias constituíram instrumento de extrema relevância nesta análise, possibilitando, assim, a compilação, manipulação, integração e geração dos dados coletados em gabinete, e em atividades de campo.

A combinação dos dados e informações levantadas e produzidas, a partir da integração por meio da concepção sistêmica, constituem a parte desta pesquisa de maior relevância, uma vez que envolve e aproveita a visão de conjunto, oferecida pelas informações, para elaborar diagnósticos e proporcionar análises úteis com vistas à utilização, principalmente, pelos gestores públicos.

Por fim, destaca-se que o sistema de projeção adotado corresponde ao Universal Transversa de Mercator (UTM), tendo como referencial geodésico o Sistema de Referência Geocêntrico para as Américas (SIRGAS 2000), sendo este o Datum oficial adotado no Brasil. Ressalta-se que a área em estudo engloba, do ponto de vista da Geodésia, a zona 23 Sul do Sistema de Referência adotado.

\section{RESULTADOS E DISCUSSÕES}

Do ponto de vista espacial, a bacia hidrográfica do Rio Mulato, engloba, no todo ou em parte, os municípios piauienses de: Amarante, Angical do Piauí, Hugo Napoleão, Jardim do Mulato, Palmeirais, Regeneração, Santo Antônio dos Milagres e São Gonçalo do Piauí, compreendendo uma área de 1.049,13 km² e um perímetro de 213,5 km (figura 2). Está inserida na microrregião do médio Parnaíba piauiense e conta com uma população estimada em 70.001 habitantes (Brasil, 2010).

Figura 2 - Localização da área de estudo 
Revista de Geografia (Recife) V. 38, No. 3, 2021

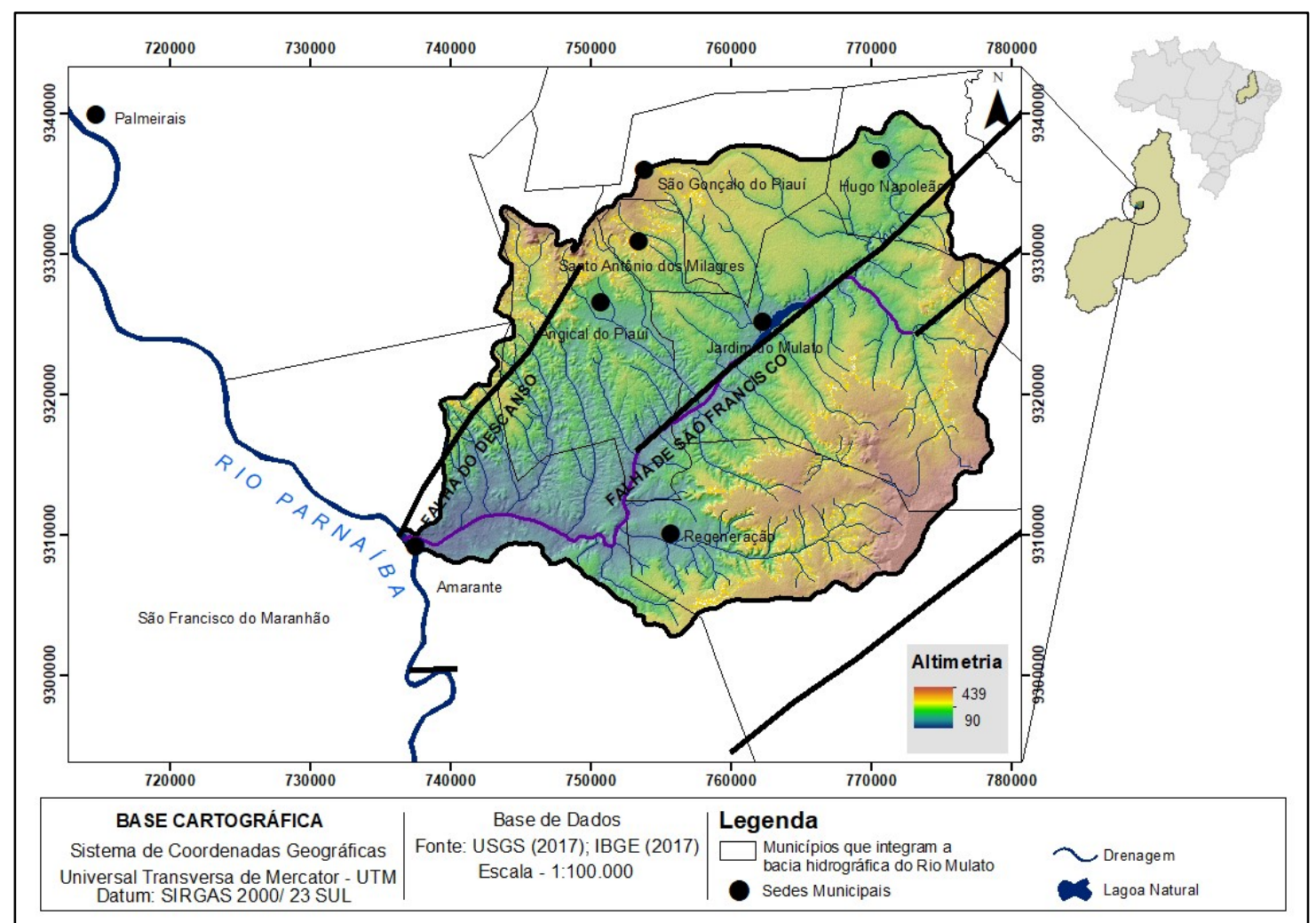

Elaboração: Autores (2020).

A área que a BHRM ocupa tem sua gênese associada à dinâmica da litosfera, resultante do lineamento transbrasiliano, e encontra-se alicerçada sobre um ambiente de estrutura sedimentar, com predomínio de formações geológicas que datam do Paleomesozoico, tais como as formações: Corda, Pastos Bons, Pedra de Fogo, Piauí e formação Sardinha (figura 3). Ao considerar a geologia da BHRM, constatou-se que há o predomínio da Formação Corda (38,21\%), seguida da Formação Piauí (33,70\%). A Formação Sardinha representa $16,17 \%$ da área total da bacia, enquanto as Formações Pedra de Fogo $(11,87 \%)$ e Pastos Bons $(0,04 \%)$ apresentam a menor extensão, abrangendo $125 \mathrm{~km}^{2}$ aproximadamente, como mostra a tabela 1 . 
Figura 3 - Mapa geológico da bacia hidrográfica do Rio Mulato, estado do Piauí

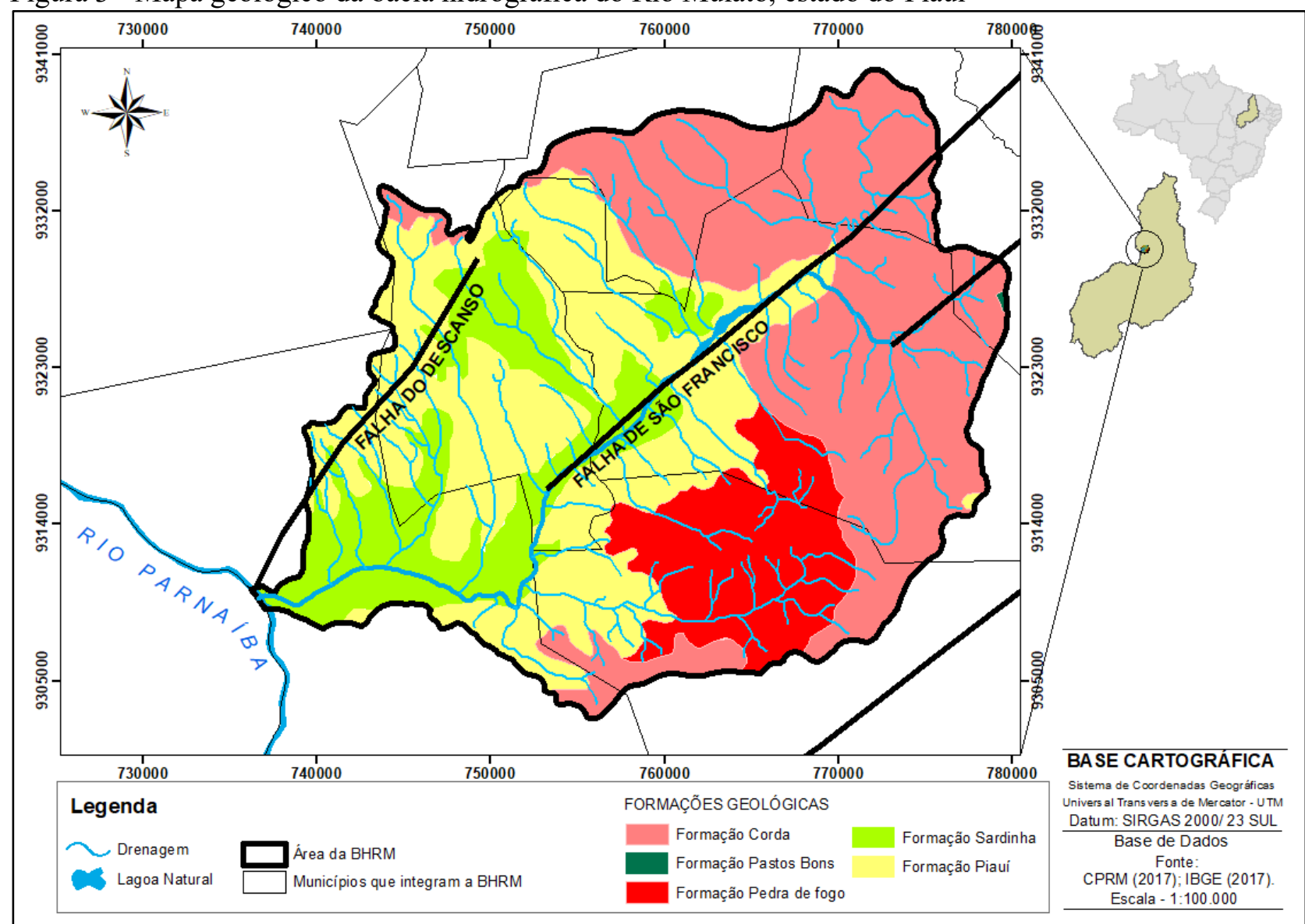

Elaboração: Autores (2020).

Tabela 1 - Quantitativo das Formações Geológicas na bacia hidrográfica do Rio Mulato, Piauí

\begin{tabular}{|c|c|c|}
\hline Formações Geológicas & Área $\left.\mathbf{( k m}^{\mathbf{2}}\right)$ & Porcentagem (\%) \\
\hline Corda & 400,83 & 38,21 \\
\hline Pastos Bons & 0,47 & 0,04 \\
\hline Pedra de Fogo & 124,54 & 11,87 \\
Piauí & 353,60 & 33,70 \\
Sardinha & 169,69 & 16,17 \\
\hline Total & $1.049,13$ & $100 \%$ \\
\hline
\end{tabular}

Fonte: CPRM (2010). Organização: Autores (2020).

No que diz respeito às formas e modelados da paisagem na BHRM, estes são decorrentes do desenvolvimento de falhas normais (São Francisco e do Descanso), as quais apresentam uma direção geral NE-SO junto aos municípios de São Francisco do Maranhão (MA) e Amarante (PI). A dinâmica dessas falhas separou dois blocos distintos, sendo que o bloco SE, em relação à falha, rebaixou-se em direção ao bloco NO, e pôs em contato na área dos municípios que integram a BHRM as formações Piauí e Pedra de Fogo gerando, assim, as linhas de fraqueza e os derramamentos vulcânicos (Brasil, 1973). Cabe destacar que além dos falhamentos regionais, ocorre grande número de fraturamentos 
por toda a bacia sedimentar, que se refletem no comportamento das formas de relevo também a nível local (Lima, 1987).

Ao considerar a declividade da BHRM (figura 4), predominam relevos planos a suave ondulado, sendo a classe de declividade de maior significância os setores com declive de 0 a $12 \%$, sendo que sua distribuição ocorre por toda sua extensão. As declividades que se apresentam no intervalo de 12 a 30\% também estão distribuídas em toda a área da bacia, principalmente próximas aos cursos d'águas, sendo o declive de 20 a 30\%, restrito a alguns pontos. Juntas, abrangem 60,51 $\mathrm{km}^{2}$ da área total da bacia hidrográfica. Por fim, a classe superior a 30\% é a que apresenta a menor área $\left(1,46 \mathrm{~km}^{2}\right)$, abrangendo apenas $0,14 \%$. Os dados de área por declividade são apresentados na tabela 2 .

Figura 4 - Mapa de declividade da bacia hidrográfica do Rio Mulato, estado do Piauí

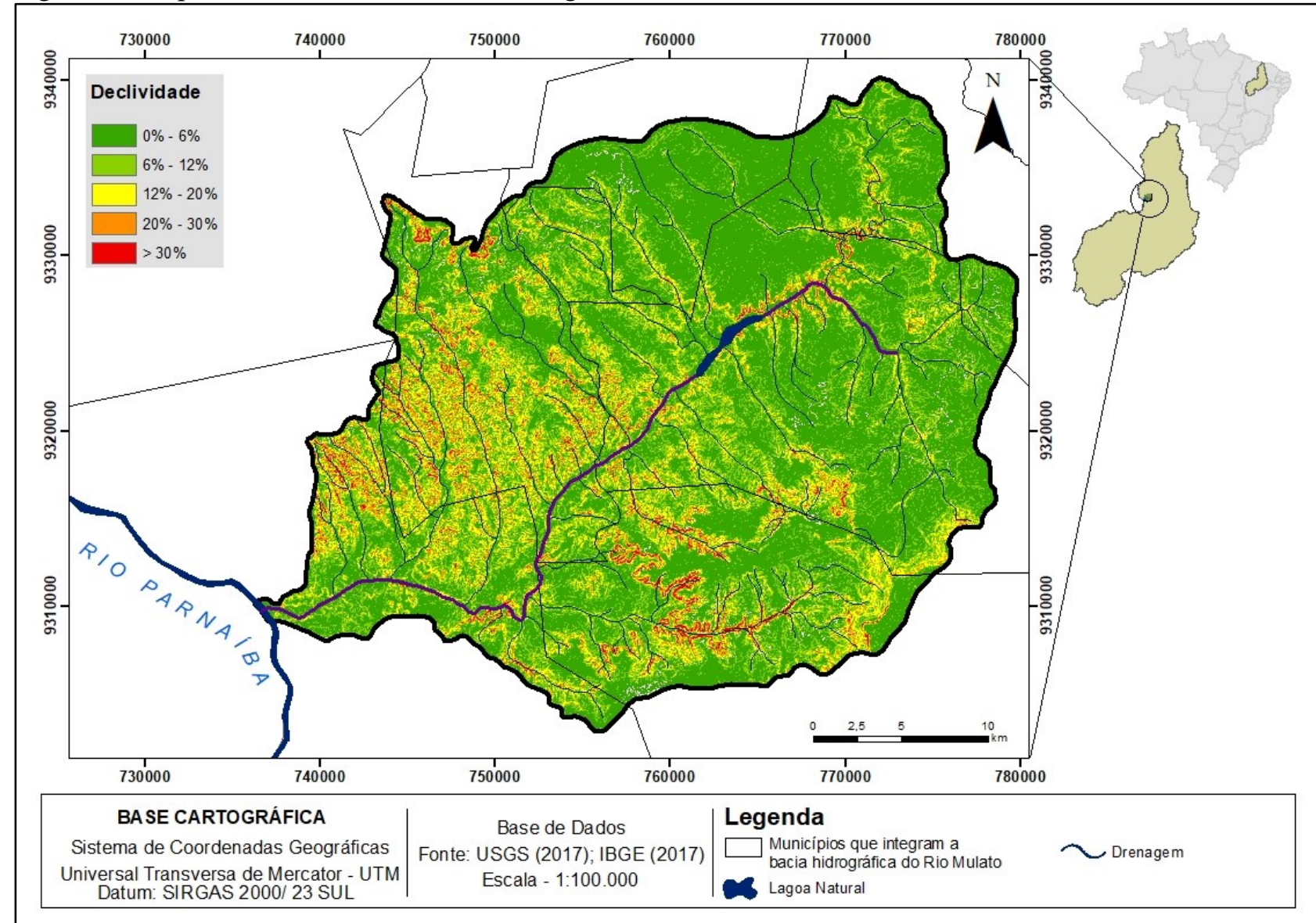

Elaboração: Autores (2020). 
Revista de Geografia (Recife) V. 38, No. 3, 2021

Tabela 2 - Classes de declividade na bacia hidrográfica do Rio Mulato, estado do Piauí

\begin{tabular}{c|c|c}
\hline Classes de Declividade (\%) & Área $\left.\mathbf{( k m}^{\mathbf{2}}\right)$ & Porcentagem \\
\hline $0-6$ & 799,10 & 76,17 \\
$6-12$ & 188.06 & 17,93 \\
$12-20$ & 54,47 & 5,19 \\
$20-30$ & 6,04 & 0,58 \\
$>30$ & 1,46 & 0,14 \\
Total & $1.049,13$ & $100 \%$ \\
\hline
\end{tabular}

Fonte: Adaptado de Ross et al. (2008). Organização: Autores (2020).

De acordo com Ross (1994), os valores de declividade indicam as características do relevo que geram energia potencial para a ocorrência de processos geomorfológicos, como erosão laminar e deslizamentos. Neste sentido, quanto a descrição morfológica, classes de 0 a $6 \%$ observou-se terreno com superfície de topografia horizontal, onde os desníveis são quase inexistentes, ao longo das planícies fluviais. Quanto aos processos erosivos, sem perda de solos.

A classe de 6 a $20 \%$ correspondem a terrenos pouco movimentados, constituídos por planaltos rebaixados, com declive suave, apresentando início de solifluxão e, em alguns setores, escoamento difuso e laminar. A classe correspondente a declive de 20 a $30 \%$ correspondem a terrenos pouco movimentados, no entanto, mais acentuado que a classe anterior, constituindo-se encostas de morros (elevações de 200 a 300 metros), predominando escoamento laminar, ravinamentos e, em determinadas áreas, movimentos de massa. A classe acima de 30\% constitui-se terrenos movimentados, com predomínio de formas acidentadas, usualmente constituídas de planaltos tabulares, variando de 300 a 400 metros, sendo comum a ocorrência de movimento de blocos.

A variável climática, baseada no comportamento pluviométrico, é considerada fundamental para compreender as análises que envolvem a fragilidade potencial. Nesse viés, o comportamento pluviométrico da área de estudo foi incluído como variável para alcançar a fragilidade potencial, pois segundo Bigarella (2003), a água atua nos processos de intemperismo, na erosão, no transporte e na deposição de sedimentos, sendo a pluviosidade um importante agente externo que ocasiona mudanças morfológicas na paisagem.

Ao considerar que a chuva é o principal agente ativo que intervém na erosão, foram selecionados 5 (cinco) postos com dados pluviométricos (figura 5), situados no interior e entorno da bacia hidrográfica, correspondendo aos municípios de Amarante, Angical do Piauí, Hugo Napoleão, Regeneração e São Gonçalo do Piauí, uma vez que estes contam com estações que dispõem de dados disponíveis para a análise pluviométrica necessária ao estudo em pauta. 
Revista de Geografia (Recife) V. 38, No. 3, 2021

Figura 5 - Espacialização dos postos pluviométricos na Bacia Hidrográfica do Rio Mulato, estado do Piauí

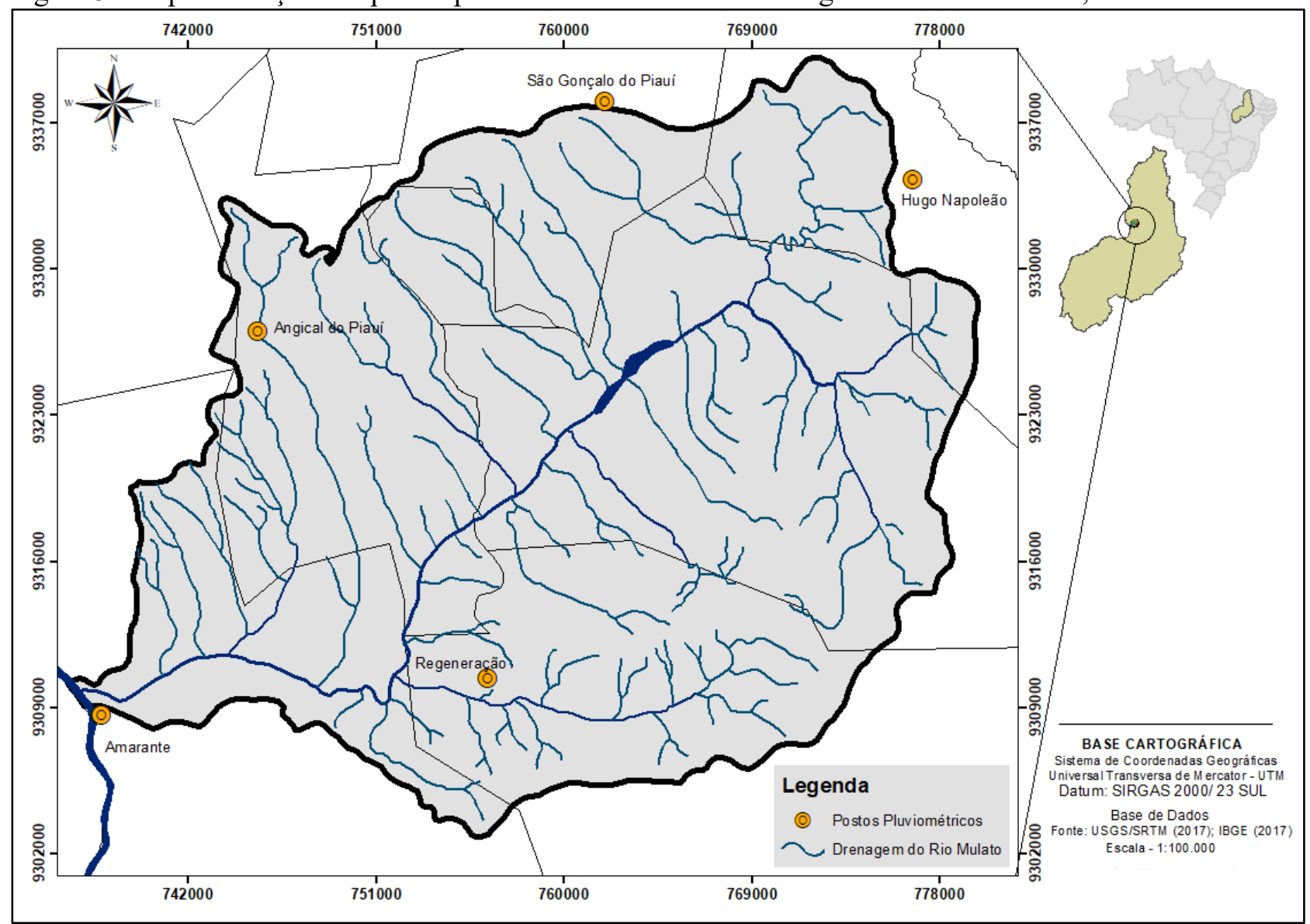

Fonte: ANA (2019). Elaboração: Autores (2020).

As figuras 6 e 7 apresentam as médias pluviométricas (mensais e anuais) conforme as normais climatológicas obtidas na Agência Nacional de Águas (Ana, 2019), numa escala temporal de onze anos (1992 a 2002), para os postos espacializados. 
Figura 6 - Médias pluviométricas mensais da bacia hidrográfica do Rio Mulato, estado do Piauí

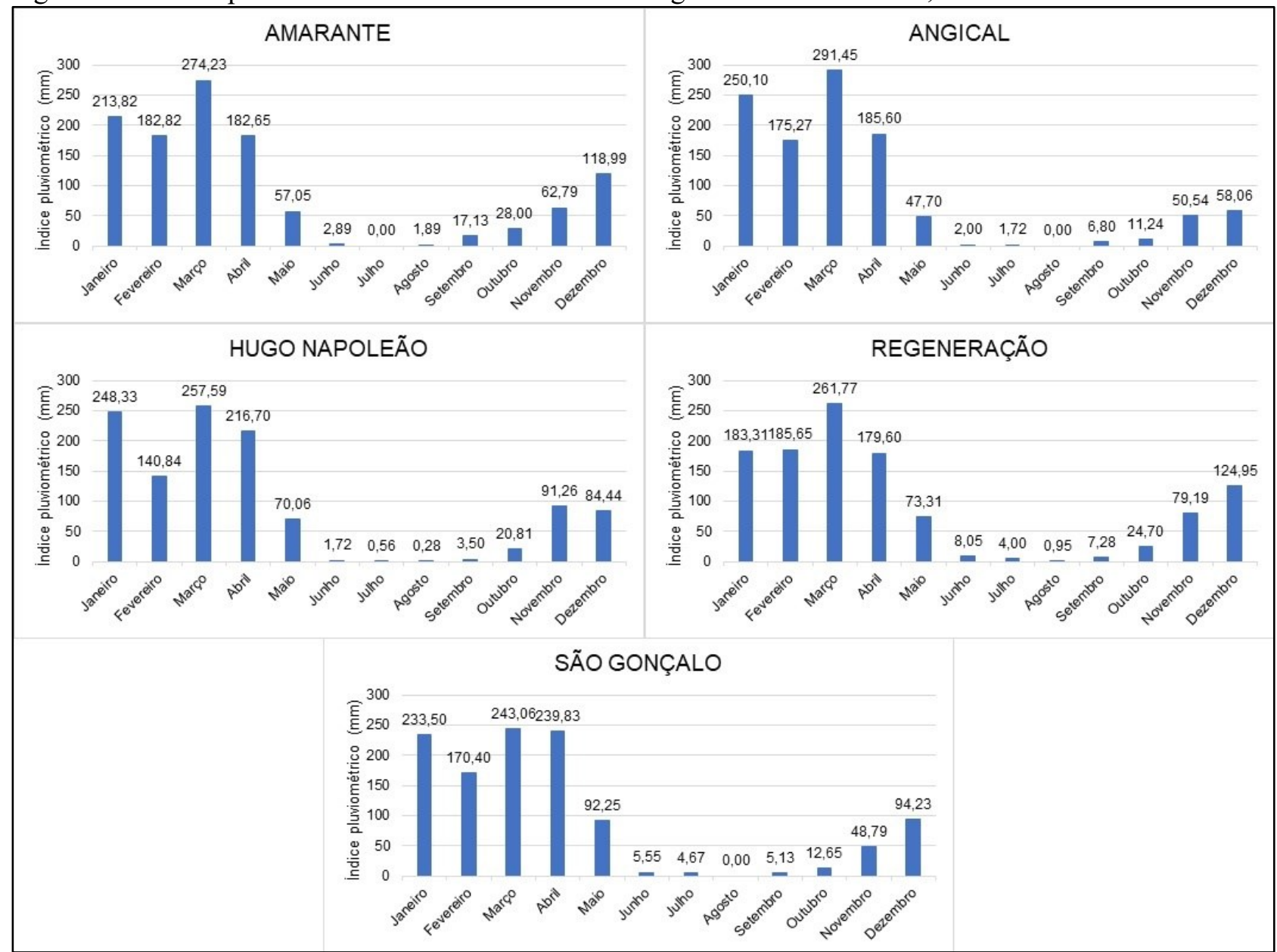

Fonte: Ana (2019). Organização: Autores (2020). 
Revista de Geografia (Recife) V. 38, No. 3, 2021

Figura 7 - Médias pluviométricas anuais da bacia hidrográfica do Rio Mulato, estado do Piauí

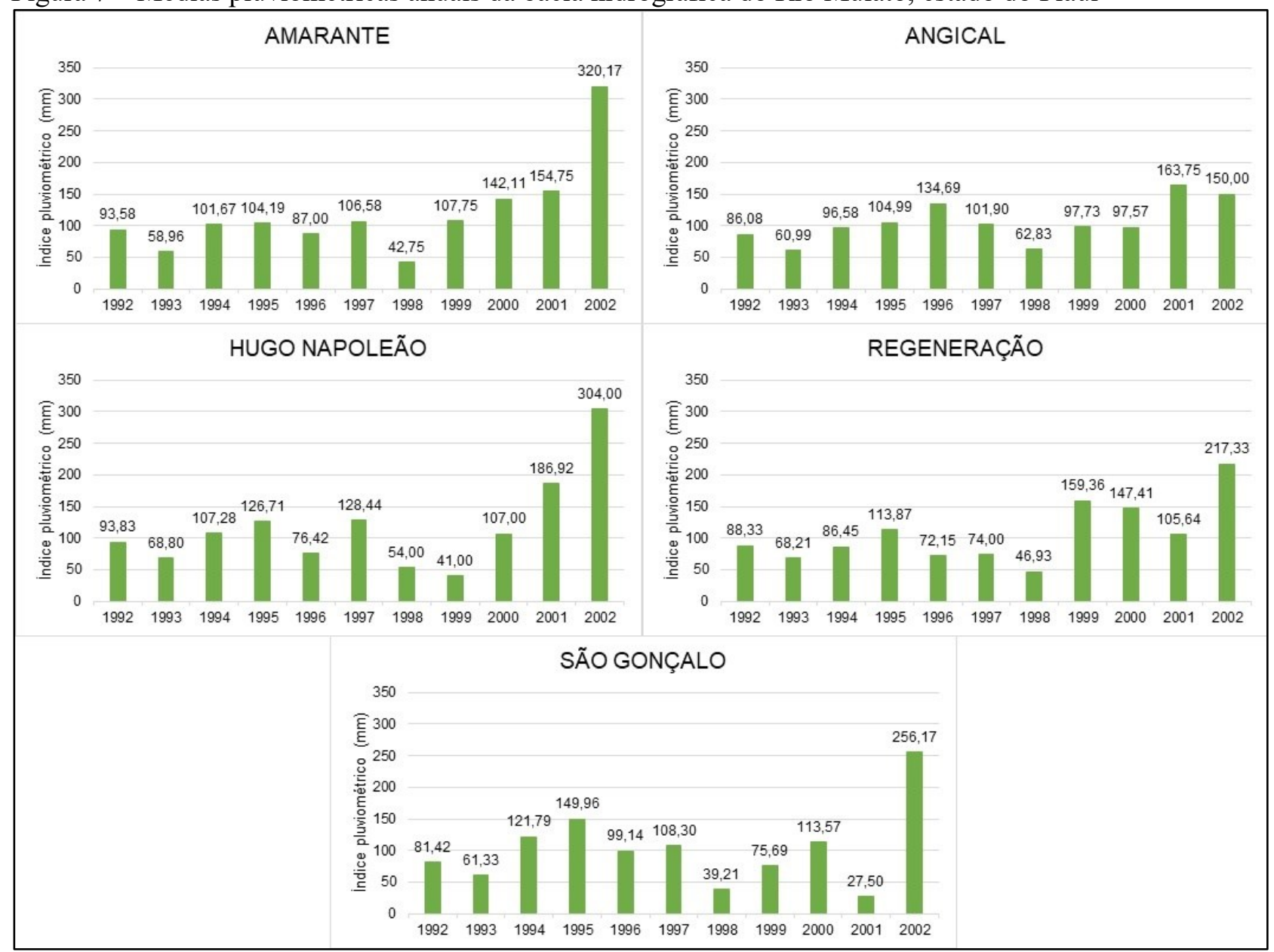

Fonte: Ana (2019). Organização: Autores (2020).

Ao analisar os respectivos dados, observa-se que $90 \%$ das chuvas se concentram durante o primeiro semestre do ano, nos meses de janeiro a abril, no verão, com médias entre 980 a $900 \mathrm{~mm}$, fato influenciado principalmente pela Zona de Convergência Intertropical (ZCIT). Em contrapartida, observa-se a irregularidade das precipitações em decorrência da má distribuição das chuvas nos meses seguintes, com médias de chuvas entre 117 a $180 \mathrm{~mm}$.

A BHRM apresenta isoietas de precipitação média anual que variam de $1.134 \mathrm{~mm}$ em toda a extensão do médio curso, a $1.319 \mathrm{~mm}$ entre o alto e baixo curso fluvial, considerando a série histórica de 11 anos utilizada nesse estudo (figura 8). Diante das características climáticas em pauta, pode-se afirmar que estas exercem forte influência nos recursos hídricos, tanto superficiais quanto subterrâneas. 
Figura 8 - Precipitação pluvial na bacia hidrográfica do Rio Mulato, estado do Piauí

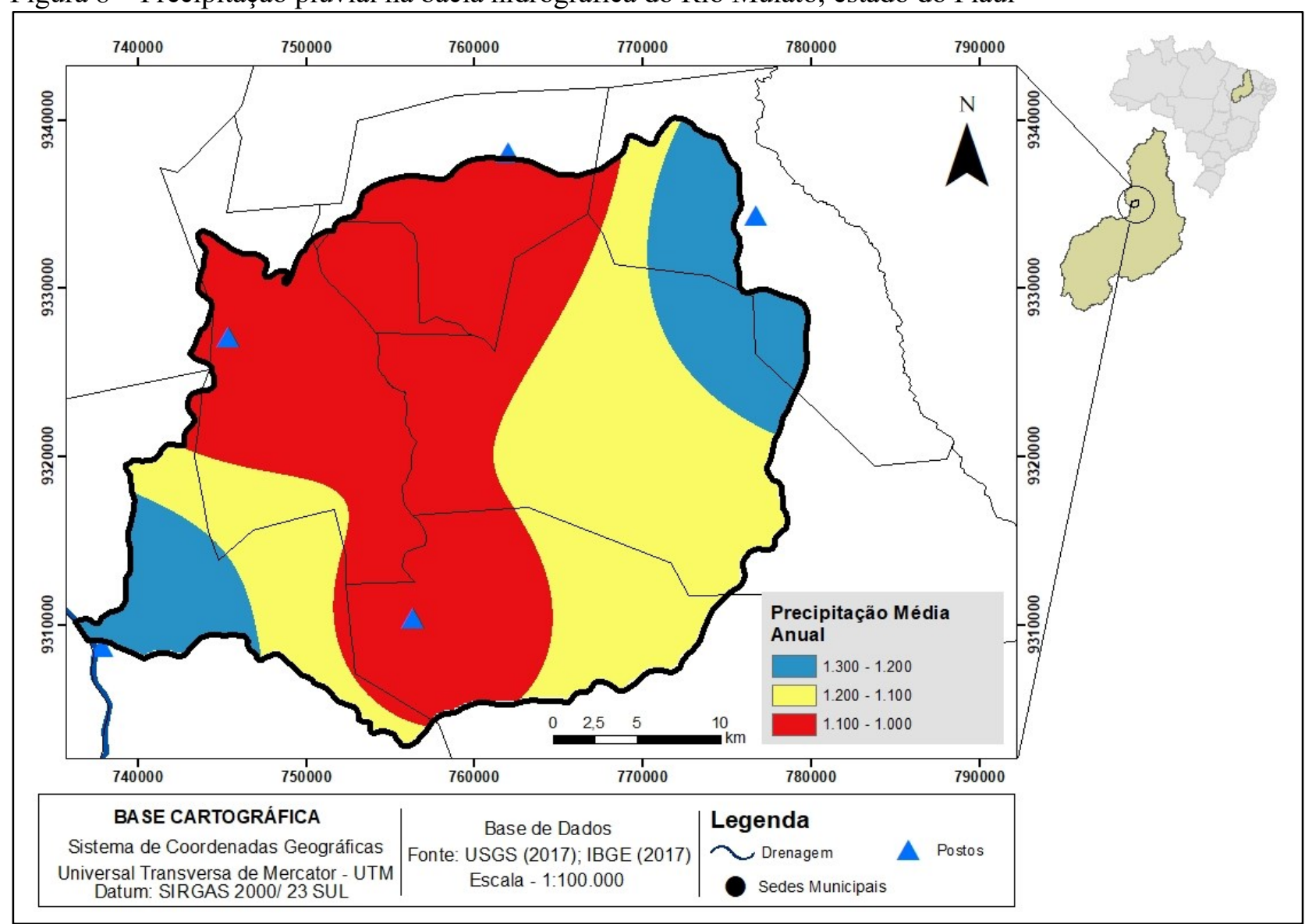

Fonte: Ana (2019). Elaboração: Autores (2020).

Por sua vez, o conhecimento pedológico aparece como sendo de fundamental importância para a compreensão das condições de fragilidade, frente aos variados processos e/ou fenômenos erosivos. Nesse viés, o conhecimento acerca das características físicas de cada tipo de solo é de suma importância para a análise da fragilidade potencial de uma determinada área (PEREIRA NETO, 2013). Ao considerar o exposto, na BHRM sobressaem os Neossolos, Chernossolos e Latossolos (figura 9).

Frisa-se que os Neossolos compreendem solos rasos e sua fertilidade está condicionada à soma de bases e à presença de alumínio, sendo neste mais limitada. Apresentam, portanto, baixa fertilidade natural (distrófico). São normalmente indicados para a preservação da fauna e flora (EMBRAPA, 2013).

Os Latossolos (amarelos) que predominam na área em estudo, são solos desenvolvidos, bastante uniforme em textura, cor e estrutura; são profundos, bem drenados, mas de baixa fertilidade natural. Sua textura areno-argilosa imprime a este solo um maior grau de fragilidade quanto à ocorrência de ravinamentos, já que as partículas arenosas possuem maior facilidade de desagregação durante o período chuvoso. Predominam em áreas de relevo plano a suave ondulado, e suas principais 
Revista de Geografia (Recife) V. 38, No. 3, 2021

limitações decorrem da forte acidez, além da pobreza de nutrientes, o que implica em um investimento inicial alto para a obtenção de boas colheitas, com uso de adubação e fertilizantes, a exemplo da prática de calagem (EMBRAPA, 2013).

Os Chernossolos são os mais férteis, uma vez que estes são resultantes da intemperização dos diques de diabásios da Formação Sardinha. Em geral, são pouco desenvolvidos, no entanto, apresentam alto potencial agrícola em virtude de suas características químicas, tendo em vista seu elevado potencial nutricional (EMBRAPA, 2013).

Figura 9 - Mapa de solos da bacia hidrográfica do Rio Mulato, estado do Piauí

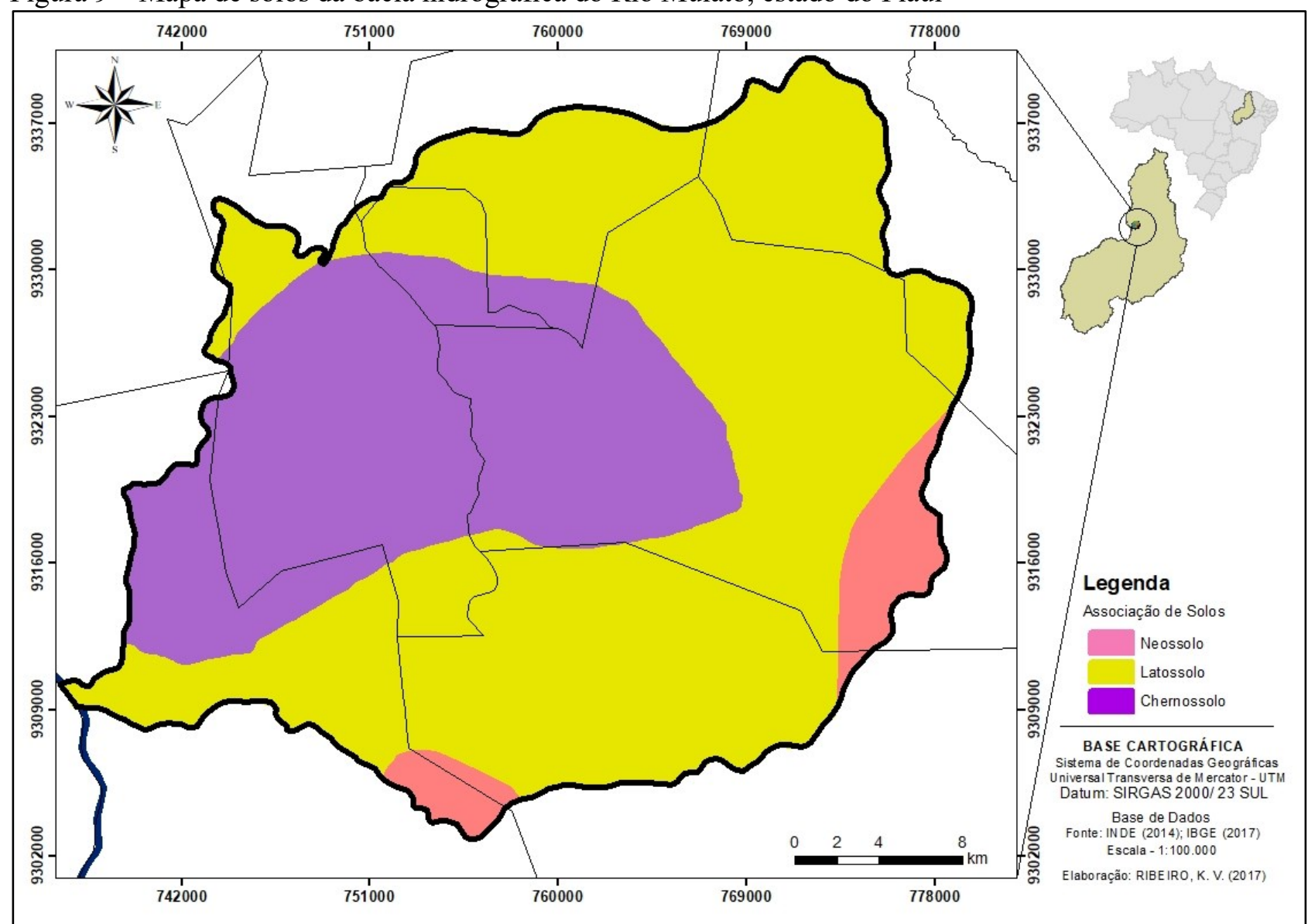

Fonte: Inde (2014). Elaboração: Autores (2020).

Contudo, é evidente a relação que os solos estabelecem com as demais componentes ambientais, inclusive com a vegetação. Neste sentido, o quadro 5 sintetiza as relações entre solos e unidades fitoecológicas encontradas na área de estudo. 
Quadro 05 - Correlação entre solos e a vegetação encontrada na bacia hidrográfica do Rio Mulato, Piaú

\begin{tabular}{|c|c|}
\hline SOLOS & VEGETAÇẦ \\
\hline Neossolos Litólicos & Caatinga arbustiva densa; caatinga arbustiva aberta \\
\hline Latossolos amarelos & $\begin{array}{c}\text { Caatinga arbustiva densa; caatinga arbustiva aberta; caatinga } \\
\text { arbórea }\end{array}$ \\
\hline Chernossolos & Floresta Estacional Decidual; Cerrado. \\
\hline
\end{tabular}

Fonte: Baptista (1975); Embrapa (2013). Organizado pelos autores (2020).

Sobre esta contextualização, são demonstrados a seguir os resultados obtidos para cada variável de maneira inter-relacionada (figura 10), quantificadas a partir do cruzamento de informações referentes à declividade, solos e clima, sendo estas determinadas em cinco classes, a saber: Muito baixa, Baixa, Média, Alta e Muito Alta, conforme a tabela 3.

Figura 10 - Mapa de fragilidade potencial da bacia hidrográfica do Rio Mulato, estado do Piauí

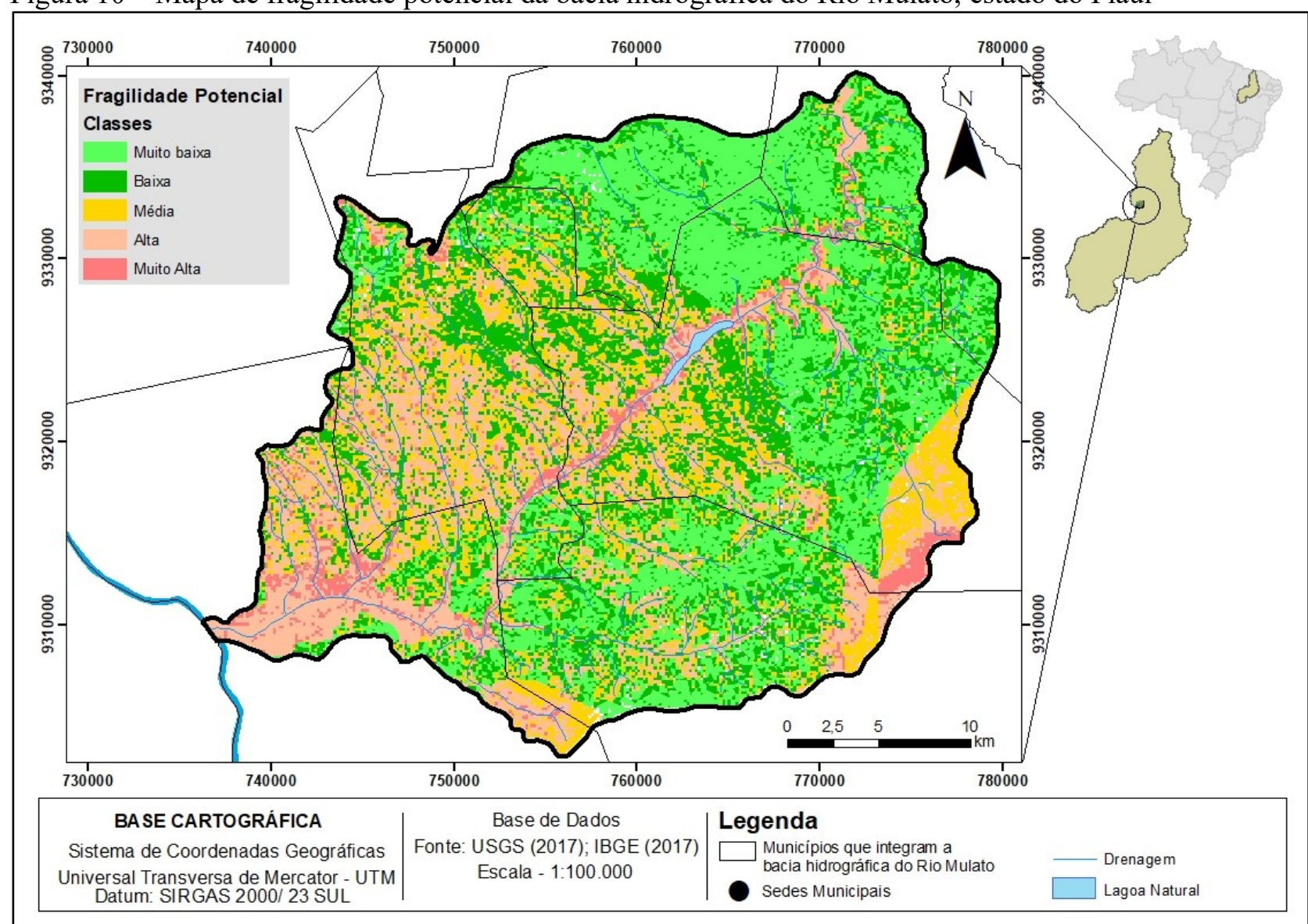

Fonte: Autores (2020). 
Revista de Geografia (Recife) V. 38, No. 3, 2021

Tabela 3 - Fragilidade Potencial da bacia hidrográfica do Rio Mulato, estado do Piauí

\begin{tabular}{c|c|c|}
\hline Classes de Fragilidade Potencial & Área $\left.\mathbf{( k m}^{\mathbf{2}}\right)$ & Porcentagem \\
\hline Muito Baixa & 301,08 & $28,70 \%$ \\
Baixa & 274,85 & $26,20 \%$ \\
Média & 196,75 & $18,75 \%$ \\
Alta & 227,68 & $21,70 \%$ \\
Muito Alta & 48,77 & $4,65 \%$ \\
Total & $1.049,13$ & $100 \%$ \\
\hline
\end{tabular}

Fonte: Ibge (2010). Organização: Autores (2020).

As classes de fragilidade potencial mais representativa correspondem aos setores muito baixa e baixa, estando dispostas por todos os setores da BHRM. Estas classes ocupam, principalmente, as áreas que apresentam declividade de 0 a 12\%, portanto de caráter fraca, caracterizada como relevo plano a suave plano, estando predominantemente associada aos Latossolos, mas também uma parte aos Chernossolos. Nestas classes, tem-se uma topografia pouco movimentada, indicando baixa instabilidade potencial, uma vez que os processos erosivos são diminutos. Juntas representam mais de $50 \%$ da área da bacia.

Por sua vez, as classes consideradas média e alta correspondem a $40 \%$ da área total da bacia, uma vez que se encontram em áreas com declive variando de 12 a 30\%, portanto, médio a forte, caracterizado por relevo suave ondulado a ondulado, e próximos aos cursos d'água, onde predominam Chernossolos e Neossolos. Observa-se que a fragilidade potencial muito alta aparece em menor proporção, ao representar pouco mais de $4 \%$, o que equivale a $48,77 \mathrm{~km}^{2}$.

De modo geral, a fragilidade potencial da BHRM apresenta uma baixa fragilidade natural e, consequentemente, menor suscetibilidade aos processos erosivos. A predominância da classe de fragilidade potencial muito baixa é reflexo de sua abrangência em áreas planas, por estarem, predominantemente, distribuída em áreas com pouco declive, agregando, assim, uma Instabilidade Potencial muito baixa. Encontra-se ainda disposta, principalmente, nos planaltos rebaixados e em alguns trechos da planície fluvial, bem como na predominância dos menores índices pluviométricos registrados para os municípios que se encontram em liame com essa classe. O que difere as características da fragilidade muito baixa para a baixa é a distribuição dos solos, sobretudo em relevo mais movimentado, uma vez que a variação da declividade é fator fundamental para a determinação destas classes.

Nas áreas de fragilidade muito alta, observa-se um relevo mais dissecado, associado às formas denudacionais tabular e campos de morros testemunhos. Pertinente aos solos, ocorrem os Neossolos Litólicos, sendo pouco profundos, distribuídos em relevo ondulado a forte ondulado, portanto, com alta suscetibilidade aos processos erosivos. Esse contexto, diante da presença de chuvas, 
favorece a intensificação desse processo, visto que a camada pedológica tende a ser mais facilmente carreada para os níveis altimétricos mais baixos, dificultando ou impedindo a regeneração da cobertura vegetal e a estabilidade desse sistema.

É importante destacar que a depender do tipo de solo em áreas com maior declive, constatase um maior grau de fragilidade a esses ambientes face às suas características genéticas. Portanto, cada uma dessas classes indicam as potencialidades, restrições ou alternativas para o desenvolvimento de atividades econômicas que ali acontecem, ou demonstram o seu potencial para as práticas de manejo que ali venham a se desenvolver, em função das condições edafoclimáticas e topográficas, fundamentais para o desenvolvimento destas atividades.

Ao partir dos resultados obtidos com relação à fragilidade potencial que a BHRM apresenta, pode-se inferir que a mesma se encontra ecodinamicamente estável, visto que as declividades pouco acentuadas e a predominância de solos com boa profundidade e drenagem, garantem a esse sistema uma estabilidade dinâmica natural.

No entanto, vale ressaltar que esta não isenta a bacia hidrográfica de problemas relacionados aos processos atuais, relacionados à erosão, uma vez que boa parte da área da bacia não conta com matas nas áreas de vertentes mais íngremes, e/ou presença de mata ciliar ao longo dos cursos hídricos, como mostra a figura 11 .

Figura 11 - A - Vertente exposta com pouca presença de vegetação arbórea; B - Ausência da mata ciliar no entorno da Lagoa do Mulato, no município de Jardim do Mulato, estado do Piauí

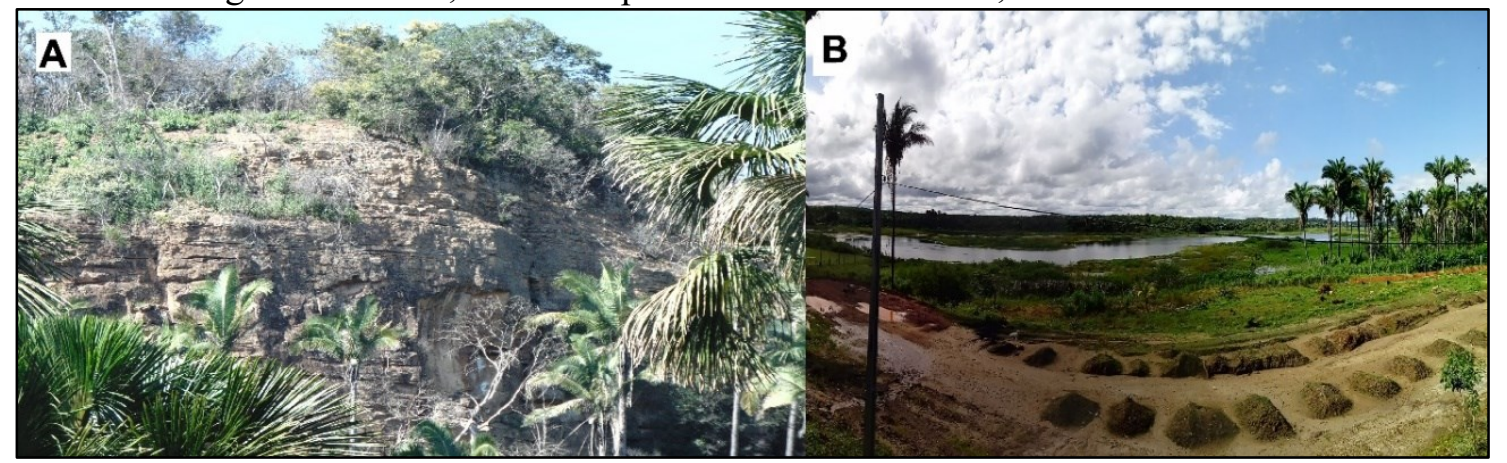

Fonte: Autores (2020).

É importante frisar que a falta de cobertura vegetal torna estas áreas mais suscetíveis e favoráveis aos processos erosivos. Além disso, os solos ficam mais vulneráveis, uma vez que apresentam uma capacidade de retenção de água menor, o que contribui para o aumento do escoamento superficial e, consequentemente, na erosão laminar.

\section{CONSIDERAÇÕES FINAIS}

Ao realizar esta pesquisa, a observação dos elementos formadores do ambiente natural da BHRM serviu para conhecer esta dinâmica, bem como seus processos atuantes. No entanto, ao se 
tratar da fragilidade potencial, deve-se levar em consideração outros fatores que estão diretamente associados aos processos erosivos, como a pluviosidade, além da litologia. Essas informações adicionais, também analisadas na pesquisa, propiciou uma maior precisão aos resultados, uma vez que analisadas em conjunto, constituem-se fatores decisivos no processo de intemperismo das rochas e na formação de solos.

Nessa perspectiva, o mapeamento da fragilidade potencial na BHRM expressa através de mapa, é um instrumento que possibilita compreender e analisar o espaço de maneira integrada, podendo, posteriormente, ser utilizado em estudos que visem o planejamento ambiental e o ordenamento do território na área de estudo. Destarte, possibilita, ainda, elaborar diretrizes para uma gestão territorial mais efetiva, levando em conta os diversos atores que estão inseridos, já que os processos decisórios necessitam de uma boa base de informações.

Portanto, a análise integrada dos aspectos físicos e o mapeamento temático, através das ferramentas de geoprocessamento, permitiram a elaboração de um produto com caráter de síntese, evidenciando, assim, os níveis de fragilidade potencial na área estudada. Esta análise adquire considerável relevância, pois sua compreensão propicia o estabelecimento de ações de cunho conservacionista voltada ao desenvolvimento regional, que considere de um lado as potencialidades dos recursos naturais e de outro as fragilidades potenciais dos mesmos.

\section{REFERÊNCIAS}

ANA. Agência Nacional de Águas. Portal HidroWeb. 2019. Disponível em: http://www.snirh.gov.br/hidroweb/apresentacao. Acesso em: 10 jan. 2019.

BAPTISTA, J. G. Geografia Física do Piauí. Teresina: Secretaria de Cultura do Piauí, 1975.

BIGARELLA, J. J. Estrutura e origem das paisagens tropicais. Florianópolis: Editora da UFSC, V. 3, 2003.

BRASIL. Ministério das Minas e Energia. Projeto RadamBrasil. Levantamento de recursos naturais, v. 2, Folha SB-23 Teresina e Folha 24 Jaguaribe, Rio de Janeiro, 1973.

BRASIL. Instituto Brasileiro de Geografia e Estatística. Manual Técnico de Geomorfologia. $2^{\mathrm{a}}$ ed. Rio de Janeiro: IBGE, 2009.

BRASIL. Instituto Brasileiro de Geografia e Estatística. Cidades. 2010. Disponível em: http://www.cidades.ibge.gov.br. Acesso em: 15 jan. 2020.

CPRM. Serviço Geológico do Brasil. Projeto Geobank. 2010. Disponível em: http://geobank.sa.cprm.gov.br/. Acesso em: 15 jan. 2018.

Dunn, M; Hickey, R. J. The effect of slope algorithms on slope estimates within a GIS. Cartography, v. 27, n. 1, p. 9-15., 1998. Doi: https://doi.org/10.1080/00690805.1998.9714086

EMBRAPA. Empresa Brasileira de Pesquisa Agropecuária. Sistema Brasileiro de Classificação de Solos. 3 ed. Brasília, DF: Embrapa, 2013. 
Guerra, A. J. T; Cunha, S. B. Geomorfologia ambiental. Bertrand Brasil, Rio de Janeiro, 2006.

INDE. Infraestrutura Nacional de Dados Espaciais. Catálogo de metadados. 2014. Disponível em: http://www.inde.gov.br/geoservicos/catalogo-de-metadados. Acesso em: 22 fev. 2018.

LEITE, E. F.; ROSA, R. Estudos da geografia física em bacias hidrográficas sob a ótica da paisagem integrada. In: XIII Simpósio Brasileiro de Geografia Física Aplicada, Anais... Viçosa, Minas Gerais, 2009.

LIMA, I. M. M. F. Relevo piauiense: uma proposta de classificação. Carta Cepro. Teresina, v.2, n. 2, 55 - 84 p, ago / dez. 1987.

PEREIRA NETO, M. C. Fragilidade ambiental da bacia hidrográfica do Rio Seridó (RN/PB Brasil). (Dissertação de Mestrado) - Universidade Federal do Rio Grande do Norte. Centro de Ciências Humanas, Letras e Artes. Programa de Pós-Graduação em Geografia, 2013.

Ross. J. L. S. Análise empírica da fragilidade dos ambientes naturais e antropizados. Revista do Departamento de Geografia da USP, n. 8, p. 63-74, São Paulo, USP, 1994. DOI: https://doi.org/10.7154/RDG.1994.0008.0006

ROSS, J. L. S; FIERZ, M. de S. M.; AMARAL, R. do. Da Ecodinâmica à Fragilidade Ambiental: subsídios ao planejamento e ordenamento territorial. In: LEMOS, A. I. G. de; ROSS, J. L. S.; LUCHIARE. A. (orgs). América Latina: sociedade e meio ambiente. São Paulo: Expressão Popular, 2008. p.67-84.

SOUZA, J. C. O. de. Identificação de geossistemas e sua aplicação no estudo ambiental da bacia hidrográfica do rio São Miguel - Alagoas. Dissertação (Mestrado), Universidade Federal de Pernambuco, Recife, 2013.

SPÖRL, C. Metodologia para a elaboração de modelos de fragilidade ambiental utilizando redes neurais. 2007. 185 folhas. Tese (Doutorado) - Faculdade de Filosofia, Letras e Ciências Humanas, Universidade de São Paulo, São Paulo, 2007.

TONELLO, K. C; DIAS, H. C. T; SOUZA, A. L. de; RIBEIRO, C. A. A. S; LEITE, F. P. Morfometria da bacia hidrografica da Cachoeira das Pombas, Guanhães - MG. Revista Árvore, Viçosa - MG, v. 30, n. 5, p. 849-857, 2006. Doi: http://dx.doi.org/10.1590/S0100-67622006000500019 